\title{
O CONHECIMENTO E O PRINCÍPIO DA INDISSOCIABILIDADE ENTRE ENSINO, PESQUISA E EXTENSÃO
}

\author{
Mário José Puhl
}

\section{RESUMO}

O trabalho tematiza a dinâmica da produção do conhecimento sob a ótica do princípio constitucional da indissociabilidade entre ensino-pesquisa-extensão e do sentido de existir da universidade, sustentado a partir da pesquisa bibliográfica e documental e de elaboração teórica. Objetiva-se debater esta temática acadêmica com vistas a contribuir para uma compreensão integrada destas dimensões do fazer acadêmico, de forma articulada entre si. Defende-se que a adoção de tal princípio projeta novas possibilidades epistêmicas e pedagógicas de reprodução, produção e socialização de conhecimentos, o que contribui na efetivação da interdisciplinaridade, além de ser um meio de transcender a dicotomia entre teoria/prática, sujeito/objeto, empiria/razão. Configura a condição de possibilidade para o fazer e o sentido da Universidade. Integrar as três dimensões da universidade não significa anular metodologias e estabelecer um método único de fazer pesquisa, produzir saberes, mas acena para a sensibilidade e abertura de cada qual às contribuições, leituras, compreensões das outras ciências e dos outros métodos. É na mútua contribuição que se afirma a especificidade de cada ciência na construção dos espaços acadêmicos e do mundo comum, afirmando uma identidade universitária.

Palavras-chave: ensino, pesquisa e extensão; conhecimento; universidade.

\section{ABSTRACT}

The work studies the dynamics of knowledge production from the perspective of the constitutional principle of the indivisibility of teaching-research-extension and the meaning of existence of the university, supported from the bibliographic and documentary research and theoretical elaboration. The objective is to discuss this issue with academic contribute the views of an integrated understanding of these dimensions of the academic do, in coordination with each other. It is argued that the adoption of such a principle design new epistemic and pedagogical possibilities for breeding, production and sharing of knowledge, which contributes to the realization of interdisciplinarity as well as being a means of transcending the dichotomy between theory / practice, subject / object, empiricism / reason. Sets the condition of possibility to do and the direction of the University. Integrate the three dimensions of university does not mean cancel methodologies and establish a single method of doing research, produce knowledge, but nods to the sensitivity and openness of each to contributions, readings, understandings of other sciences and other methods. It is in the mutual contribution which states the specificity of each science in the construction of academic spaces and the ordinary world, claiming a university identity.

Keywords: teaching, research and extension; knowledge; university.

\section{Introdução}

As universidades brasileiras têm um sentido de existir, uma razão de ser, e sua práxis pedagógica consubstancia-se no princípio republicano constante no artigo 207 da Constituição Federal de 1988 (2002), o qual afirma a indissociabilidade entre as dimensões do ensino, da pesquisa e da extensão. O princípio da indissociabilidade entre ensinopesquisa-extensão, no ensino superior, busca superar a dicotomia entre teoria/prática, 
sujeito/objeto, empiria/razão? O que fundamenta o princípio da indissociabilidade entre ensino-pesquisa-extensão, no ensino superior? Quais são as bases teóricas que sustentam esta compreensão? Como este princípio se relaciona com as finalidades da Universidade?

A indissociabilidade entre ensino-pesquisa-extensão possibilita novas formas pedagógicas de reprodução, produção e socialização de conhecimentos, efetivando a interdisciplinaridade. Ela oportuniza também superar a dicotomia entre teoria/prática, sujeito/objeto, empiria/razão, constituindo outro fundamento epistêmico. Essas dicotomias são resultados do modo de pensar binário e linear elaborado de acordo com o modelo de pensamento que simplifica e opera pelo princípio do terceiro excluído, do tipo, ou é isso ou é aquilo. Para a lógica clássica, algo não pode ser e não ser ao mesmo tempo.

No entanto, tais concepções dicotômicas podem ser transcendidas quando compreendemos o conhecimento com base em outros referenciais. Entre eles destacamos as condições de possibilidade do conhecimento embasadas na teoria da Kant $(2009 ; 2005)$ Sendo assim, o estudo, a problematização e a discussão dessa temática contribui na busca de perspectivas para a ação do docente inserido nesse espaço, principalmente no que se refere a sua importante tarefa em relação ao conhecer. Por sua vez, ignorá-la significa abdicarmos de tratar elementos fundamentais da atuação do professor de ensino superior.

\section{0 princípio da indissociabilidade}

A abordagem da relação entre extensão, pesquisa e ensino tem sido alvo de muitos debates e estudos, principalmente na história recente. A sustentação de sua indissociabilidade parece envolver mais um desses enigmas que não encontram uma saída e nem se resolvem, de forma adequada e satisfatória, quando considerados sob o enfoque de uma lógica disjuntiva. Nosso propósito é, pois, buscar compreender essa relação sob o viés de princípios que contribuam na fundamentação do caráter triuno das dimensões, considerando tal conceito-hipótese como possibilidade para o conhecimento. Antes de passarmos à tentativa de argumentação e sustentação desta ideia inicial, convém apresentarmos o que entendemos por princípio, que faremos embasados em algumas teorias filósofos.

A Carta Magna (2002) estabelece um princípio no artigo 207, caput, que é o da indissociabilidade entre ensino, pesquisa e extensão, nos seguintes termos: "Art. 207. As universidades gozam de autonomia didático-científica, administrativa e de gestão financeira e patrimonial, e obedecerão ao princípio de indissociabilidade entre ensino, pesquisa e extensão" (BRASIL, 2002, p. 123). Mas o que é um princípio?

Toda ação tem um ponto de partida na qual está expressa uma intencionalidade, visto que não se parte de qualquer lugar para chegar a algum lugar previsto anteriormente. O ponto de partida e o possível lugar ou momento de chegada inter-relacionam-se como o caminho a ser percorrido, a forma como este percurso será realizado e por quem será realizada esta caminhada.

Em sua acepção própria, o vocábulo princípio traduz a idéia "de origem, começo, causa primária" [...]. E esta "é a idéia que está presente na expressão princípio de autonomia universitária a designar não um princípio constitucional ou uma norma constitucional de princípio norma programática -, mas um princípio universitário, ou mesmo de direito educacional por ser inerente à atividade universitária, e não à ordem jurídica, no sentido de orientação axiológica para a compreensão do sistema jurídico nacional" [...] (FÁVERO, 1998, p. 61). 
O princípio não é estático, absoluto e imutável. É uma referência constituída que baliza, orienta, guia a ação a ser empreendida. É um ponto de partida ou fundamento de um processo qualquer. Não representa propriamente o percurso realizado ou resultado obtido e, portanto, algo concluso.

Os filósofos da Grécia do século VII antes de Cristo, dentre outras preocupações e debates buscavam uma explicação racional, lógica e sistemática sobre o Universo. Uma cosmologia que explicasse a origem do universo, a origem e a causa das transformações das coisas. Esses filósofos procuravam saber, com base na razão, nas observações, o princípio substancial, a arché, existente em todos os seres materiais. Pretendiam, pois, definir o princípio primeiro do qual se originam todas as demais coisas existentes no Universo.

Dentre os filósofos deste período histórico está Anaximandro. Para ele não há uma única substância material como o princípio original dos seres, a arché. No entender deste pensador grego o princípio fundante é algo que transcende a capacidade humana do observável, isto é, não se situa numa realidade ao alcance dos sentidos empíricos, o qual ele denominou de ápeiron, termo grego que significa o indeterminado, o ilimitado, o infinito. O ápeiron seria a massa geradora dos seres que contém em si mesma todos os elementos contrários. Anaximandro caracteriza princípio como o ponto de partida, o fundamento de um processo ou causa primeira de algo.

Platão (2008) segue a linha de pensamento de Anaximandro na busca de estabelecer a causa universal de todas as coisas. Entende que o princípio, a causa de todas as coisas, é a inteligência, cuja ideia vem de outro pensador grego, Anaxágoras. Platão sustenta a tese de que

[...] é a inteligência que põe tudo em ordem e que é a causa universal. Esta causalidade me encheu de alegria, em virtude do interesse que eu sentia, num sentido, de fazer da inteligência a causa de todas as coisas. Se é assim, pensava, o espírito ordenador ordena todas as coisas e dispõe cada uma da melhor maneira possível (PLATÃO, 2008, p. 225).

Diverso do pensamento de Platão, segundo o qual a fonte do conhecimento são as ideias, Aristóteles (2009b) defende a teoria de que a finalidade elementar das ciências é desvendar a essencialidade dos seres, buscando uma definição para cada qual em termos reais. A realidade é constituída por uma multiplicidade de seres que são possíveis de serem percebidos pelos sentidos, pela empiria. É pela observação que se constata a existência de inúmeros seres individuais, factíveis, que são percebidos pelos sentidos humanos e que constituem a base do conhecimento humano.

É pela indução que ocorre o processo intelectual elementar de aquisição do conhecimento. A partir da existência de cada ser particular que poderemos atingir a essência dos seres, através da dinâmica do conhecimento que parte do específico para o genérico. É pelo conjunto de características de cada uma das escolas que chegamos à formação do conceito geral escola e cada escola contém uma particularidade do conceito geral.

São as definições essenciais que possibilitam às ciências seu uso de forma generalizada. O método indutivo de conhecimento, conforme Aristóteles (2009b) torna possível que o ser humano alcance conclusões científicas, de validade universal. Parte dos dados ou observações sensíveis, concretas e formula os conceitos gerais.

No entanto, as coisas e os seres particulares não são estáticos, eles podem mudar. Cada ser é integrado pela dimensão do ato e da potência. $\mathrm{O}$ ato é a manifestação atual do ser, o que ele é no presente. É o existente. A potência do ser constitui a possibilidade do 
vir a ser. É a probabilidade futura do ser, de algo. O ser é integrado pela dimensão do estático (da conservação), o que ele é - ato - e pela possibilidade da transformação, da mudança, do que ele poderá ainda ser - a potência.

A mudança, a passagem de uma situação à outra não é fruto do acaso. A mudança é causada. Causa é "tudo aquilo que determina a realidade de um ser", afirma Aristóteles (2009a, p, 39). Este filósofo identifica quatro causas fundamentais da existência de uma coisa, de um ser, distintas entre si, mas complementares: a material, refere-se à matéria da qual um determinado objeto é feito; a formal, é o que uma coisa é, sua aparência exterior, que assim a define; a causa eficiente, diz respeito à quem produz diretamente o objeto; e, a causa final, pertinente à intencionalidade, à finalidade, ao sentido de ser de algo, de um objeto, para que serve, qual a sua função, razão de ser.

É pois manifesto que as ciências a adquirir é a das causas primeiras (pois dizemos que conhecemos cada coisa somente quando julgamos conhecer a sua primeira causa); ora, causa diz-se em quatro sentidos; no primeiro entendemos por causa a substância e a qüididade (o "porque" reconduz-se pois à noção última, e o primeiro "porque" é causa e princípio); a segunda causa é a matéria e o sujeito; a terceira é a de onde vem o início do movimento; a quarta causa, que se opõe à precedente, é o "fim para que" e o bem (porque este é, com efeito, o fim de toda geração e movimento) (ARISTÓTELES, 2002, p. 94)[1].

Conforme a teoria aristotélica a causa final determina a causa formal porque é a finalidade da existência de algo, de um ser, que define o que os seres efetivamente são. É a causa final que produz, gera, provoca o movimento, a transformação da realidade, da coisa. É pela causa final que as coisas mudam, determinando a passagem da potência para o ato. isto é,

É a atividade racional, o ato de pensar que constitui a essência da condição humana,

[...] aquilo que é o melhor e o mais prazeroso a cada criatura é o que é próprio à natureza de cada uma; em conformidade com isso, a vida do intelecto representa a vida melhor e mais prazerosa para o ser humano porquanto o intelecto, mais do que qualquer coisa, é o ser humano. Conseqüentemente, essa vida será a mais feliz (ARISTÓTELES, 2009b, p. 309).

Aristóteles (2002) afirma que o princípio tem uma relação direta com o processo de conhecimento, a forma de conhecer. Exemplo desta tese são as premissas de uma demonstração ou os axiomas matemáticos a partir dos quais inferimos ou realizamos os cálculos. Acrescenta-se à idéia do princípio sua correspondência à causa, visto que todas as causas são princípio, pontos de partida do conhecer.

Por sua vez, Kant (2009) realiza dois movimentos relativos à teoria do princípio e de sua relação com o conhecimento. De um lado, restringe o uso do termo ao campo do conhecimento, quando define esta categoria conceitual como "toda propriedade geral, mesmo extraída da experiência por indução, que possa servir de premissa maior num silogismo". Por outro lado, sustenta o pensamento do "princípio absoluto" ou "princípio em si", que seriam conhecimentos sintéticos genuínos e puramente racionais aos quais a razão recorre no seu uso dialógico para conhecer.

Diferente de alguns filósofos anteriores, este filósofo entende que a razão humana possua a capacidade de conhecer as coisas em si mesmas, de conhecer a realidade em si mesma, os primeiros princípios, as principais causas da existência de todas as coisas, 
porque considera estas posturas como pretensões metafísicas. Kant (2009) defende a tese de que o ser humano só conhece as coisas tais como são organizadas pela estrutura interna e universal da razão humana. No entanto, a pessoa não pode saber se tal estrutura interna de sua mente corresponde ou não à organização da realidade em si mesma. Sua preocupação central está dirigida, neste diapasão, às condições de possibilidade do conhecimento verdadeiro como conhecimento possível para a condição humana, cujo tema será abordado no terceiro capítulo do texto.

\section{Intencionalidade e identidade universitária}

A interligação do ensino, pesquisa e extensão relaciona-se com os objetivos e as intencionalidades da existência da universidade. Uma vez que cada uma dessas dimensões está presente há mais ou menos tempo no contexto universitário e, mais recentemente, em outras instituições de ensino superior, o desafio é pensá-las e organizá-las articuladamente de modo a se concretizarem ou se efetivarem na prática.

O artigo 207, caput, da Constituição Federal vigente, expressa uma concepção de ensino superior, uma compreensão de como deva ser realizada a educação neste nível de ensino e um paradigma de universidade. Este preceito constitucional define a

[...] universidade como instituição e ideal de referência para o conjunto das IES. Nesse sentido, a indissociabilidade entre ensino, pesquisa e extensão visa a concretização de um padrão de qualidade de oferta da educação superior, assim como a limitação de fortes constrangimentos estatais, mercadológicos ou de outra natureza que consubstanciem dependência nos processos de ensino, de produção e de difusão do conhecimento (CATANI; OLIVEIRA, 2007, p. 79).

A universidade, ao longo de sua existência, passou por diversas transformações, sejam elas quanto à sua organização, forma de funcionamento e estruturação, dinâmicas administrativas, seu financiamento e formas de produção e socialização de conhecimentos. No entanto, há um eixo, um núcleo central, que dá identidade a todas as universidades e que persiste ao longo do tempo: elas são um lugar do conhecimento. É o conhecimento a razão de sua existência. As universidades são o lócus de formação integral da pessoa a qual passa pela tridimensionalidade do fazer universitário, enunciada na legislação pátria.

Ela está situada e inserida em um contexto social, cultural, político, econômico, ambiental, dentre outros, com os quais dialoga, é influenciada e os influencia. A identidade política da universidade está relacionada aos princípios e normas legais que a república lhe atribui, lhe determina realizar, através da legislação atinente. As políticas educacionais e, em especial, a universitária estabelecem quais são as grandes intencionalidades deste nível de ensino e o caráter social destas instituições de ensino superior. Dentre outras está o da integração entre o ensino, a pesquisa e a extensão. A separação destas três dimensões rompe com os objetivos e o sentido de ser da universidade. O princípio da universidade relaciona-se com as intencionalidades da instituição educacional.

\section{O princípio da indissociabilidade e a condição de possibilidade do conhecimento humano}

A relação inseparável das três dimensões principiológicas das universidades brasileiras necessita ser tematizada, ou no dizer de Heidegger (2012, p. 40), há que se fazer $\mathrm{o}$ indiciamento formal deste postulado epistemológico. A possibilidade do questionamento inicial é condição para a busca do conhecimento. "Todo questionar é um buscar. Toda busca retira do que se busca a sua direção prévia. Questionar é buscar cientemente o ente 
naquilo que ele é e como ele é. A busca ciente pode transformar-se em "investigação" se o que se questiona for determinado de maneira libertadora". O propósito constitucional e os desafios à construção de saberes científicos levam-nos a questões pertinentes à, como conhecemos? Quais são condições de possibilidade para a realização do conhecimento? Por que a educação constitui-se em uma práxis social? Que relação se estabelece entre o princípio da indissociabilidade constitucional e as intencionalidades das universidades e a teoria do conhecimento?

Para buscar algumas respostas, ainda que provisórias, às indagações acima expostas, considera-se importante reportar-nos a duas teorias filosóficas que possam sustentar o princípio da inseparabilidade das dimensões do ensino, pesquisa e extensão no ensino superior, que são a teoria de conhecimento de Kant.

Um dos filósofos de maior expressão do iluminismo alemão, Kant em seu trabalho O que é a ilustração expressa seu otimismo em relação à possibilidade de o homem guiarse por sua própria razão, alcançar sua condição de maioridade, tonando-se independente em relação às ideias de outras pessoas, da tutela alheia. O processo de ilustração compreendido como a "saída do homem de sua menoridade" e a tomada de consciência por ela da autonomia da razão na fundamentação das escolhas e ações humanas, requerem a educação e a instrução.

A ilustração é a libertação do ser humano de sua incapacidade da qual ele
próprio é o culpado. A incapacidade significa a incapacidade de servir-se
de sua inteligência sem a guia de outrem. Esta incapacidade é sua culpa
porque sua causa reside, não na falta de inteligência, mas na falta de
decisão e coragem para servir-se, por si mesmo, dela sem a tutela de
outrem. Sapere aude! Tem a coragem de servir-te de tua própria razão:
eis aqui o lema da ilustração (KANT, 2011, p. 23 ).

A condição humana caracteriza-se pela racionalidade e pela liberdade. Cabe à filosofia responder, no entender de Kant às seguintes questões: O que posso saber? Como devo agir? O que posso esperar? O que é o ser humano? No intuito de responder a estas indagações fundamentais o pensador iluminista desenvolveu um exame crítico da razão, com o fito de estabelecer as condições de possibilidade nas quais de realiza o conhecimento humano, visto que uma das suas preocupações fulcrais é o conhecimento e com a qual nos centramos neste trabalho.

Para este filósofo, há duas formas básicas de realizar o conhecimento, o a posteriori (o empírico) e o a priori (o puro, o racional). O conhecimento empírico é obtido a partir dos dados fornecidos pelos sentidos, pela experiência. É posterior à experiência realizada. O conhecimento puro é aquele que não depende dos dados dos sentidos, da experiência, pois antecede a experiência fática. É resultado de operações racionais, do pensamento puro. Um conhecimento que possibilita estabelecer juízos, ou seja, uma afirmação universal que não depende de nenhuma condição real. Igualmente, ela é uma afirmação necessária. Um exemplo de um juízo universal e necessário é o de que duas linhas retas paralelas jamais se encontram no espaço.

Os juízos universais e necessários resultam da razão pura, do conhecimento produzido pelo pensamento em si, enquanto que o conhecimento sensível não apresenta esta característica. Para Kant todo conhecimento inicia com a experiência sem, porém, resumir-se à ela e nem conclui-se com ela e, tampouco, nem todo ele tem por origem a empiria. 
Não há dúvida de que todo o nosso conhecimento começa com a experiência; [...]. Segundo o tempo, portanto, nenhum conhecimento em nós precede a experiência, e todo o conhecimento começa com ela.

Mas embora todo o nosso conhecimento comece com a experiência, nem por isso ele se origina justamente $d a$ experiência. Pois poderia bem acontecer que mesmo o nosso conhecimento de experiência seja um composto daquilo que recebemos por impressões e daquilo que a nossa própria faculdade de conhecer (apenas provocada por impressões sensíveis) fornece de si mesma, cujo aditamento não distinguimos daquela matéria-prima antes que um longo exercício nos tenha chamado a atenção para ele e nos tenha tornado aptos a abstraí-lo (KANT, 2009, p. 23).

Na dinâmica do conhecimento ocorre a formulação de juízos, os quais Kant caracteriza como juízos analíticos e juízos sintéticos. Um juízo é analítico quando o predicado do enunciado já se encontra no sujeito. Os predicados enunciados caracterizam, definem o próprio sujeito. O conteúdo do sujeito é explicado no próprio enunciado e basta analisar o sujeito para inferir o predicado. Um exemplo de juízo analítico é que o quadrado possui quatro lados iguais. Ao analisar o quadrado, o sujeito, deduzimos, necessariamente, o predicado: possui quatro lados. O sujeito é explicado ou se explica pela sua enunciação.

O juízo sintético é realizado quando se estabelece uma relação entre o sujeito e o predicado na qual o predicado fornece informações novas sobre o sujeito. Os juízos sintéticos produzem novos conhecimentos ou ampliam os saberes já construídos de um determinado fato ou realidade. Ocorre nestes juízos uma formulação de uma síntese entre o sujeito e um predicado. Uma situação desta relação é a que se estabelece entre o calor e a dilatação dos corpos. Quando se afirma que o calor dilata os corpos, o predicado causa da dilatação não está analiticamente inscrita no sujeito, o calor. Realizando uma relação causal entre predicado e sujeito, opera-se uma síntese. Um novo conhecimento é formado sobre o sujeito por meio do predicado. O conhecimento resultada desta relação complexa entre a sensibilidade e o entendimento, porque "existem dois troncos do conhecimento humano: a sensibilidade e o entendimento. Através da primeira se nos dão os objetos, através da segunda, os pensamos", define Leite (2010, p. 38).

Seguindo os pensamentos de Kant, Chauí (1999) entende que a razão constitui o sujeito conhecedor. A razão é uma estrutura vazia, uma forma pura sem conhecimentos, com uma dimensão universal, a mesma em todas as pessoas, em todos os tempos e lugares. É uma estrutura que nasce com a pessoa, pois não é adquirida pela e na experiência. Sendo inata, "a razão é, do ponto de vista do conhecimento, anterior à experiência" (idem, p. 78).

Mas como a razão, sendo anterior à experiência e uma estrutura universal vazia, adquire conhecimentos? Recorrendo à Chauí (1999, p. 78) infere-se que os conteúdos nos quais a razão pensa, sobre os quais reflete, dependem da experiência, pois sem esta, a razão permaneceria vazia e nada conheceria, porque "a experiência fornece a matéria (os conteúdos) do conhecimento para a razão e esta, por sua vez, fornece a forma (universal e necessária) do conhecimento. A matéria do conhecimento, por ser fornecida pela experiência, vem depois desta e por isso, no dizer de Kant, é a posteriori".

A razão realiza a síntese a partir da sua estrutura geral, universal, a partir dos conteúdos fornecidos pela empiria, os quais podem variar no tempo e no espaço, transformar-se em novas experiências ou orientá-las, que por sua vez fornecerão novas matérias à razão a qual irá transformá-las em saberes racionais, filosóficos, científicos, elaborando-se conceitos, compreensões com caráter universal, visto que resultam da estrutura universal que é a razão. 
Os dados da experiência são organizados pelas categorias conceituais da razão as quais "são instrumentos racionais com os quais o sujeito do conhecimento organiza a realidade e a conhece", finaliza Chaú (1999, p. 78), dado que possuem o caráter da universalidade e da atemporalidade. É a universalidade e a necessidade das categorias que possibilita produção dos conhecimentos científicos e lhes dão a sua validade.

$\mathrm{O}$ conhecimento se realiza na medida em que interagem as condições materiais de conhecimento oriundas da experiência, que os sentidos captam e as condições formais do conhecimento, o que a razão humana realiza e processa com as percepções, informações advindas da realidade observada. A experiência é o início do conhecimento, mas ela não realiza ou produz saberes por si mesma. Os sentidos absorvem da experiência informações que a razão organiza, elabora, sistematiza e conceitua. A razão opera, reflete com aquilo que a experiência alcança, pois nela já se encontram as condições formais - a estrutura universal e atemporal - que torna possível o conhecimento. Acontece a simbiose da razão prática com a razão pura, bem como a formulação se juízos analíticos e sintéticos.

A relação de um sujeito com um predicado (considerando apenas os juízos afirmativos) é viável de duas maneiras: ou o predicado $B$ pertence ao sujeito A como algo contido nele, ou B é estranho ao conceito A, mesmo junto dele. Chamo o primeiro caso de juízo analítico, e o segundo de sintético. Portanto, juízos analíticos (afirmativos) são aqueles em que a conexão do predicado com o sujeito for pensada por identidade; juízos sintéticos são aqueles em que essa conexão for pensada sem identidade. Os primeiros também poderiam ser chamados de juízos explicativos, e os segundos, de juízos extensivos (KANT, 2009, p. 18).

Na relação dialógica entre o sujeito cognoscente e a realidade cognoscível, da qual resultam os conhecimentos, o primeiro não pode acreditar que possa conhecer a realidade tal como está em si mesma. A verdade não está nos fatos, no mundo, pois a razão está em quem busca o saber e não naquilo que se deseja conhecer. O mundo é o mundo construído por quem o assim compreende. Dito de outra maneira, o mundo no qual se vive é o mundo construído por aqueles que nele vivem. A caracterização do mundo é resultado de quem o assim define, pois vivemos no mundo que fazemos.

O único mundo que o Homem conhece é o empírico mundo dos fenômenos, das "aparências", e esse mundo só existe na medida em que o homem participa de sua construção. Só podemos conhecer as coisas relativas a nós mesmos. [...] Ou melhor, a "realidade" para o Homem é necessariamente a que ele mesmo criou; o mundo em si deve permanecer algo que somente pode ser pensado, jamais conhecido (TARNAS, 2001, p. 370).

A coisa em si, o absoluto, o transcendental não é possível se ser conhecido, diz Kant (2009). Somente podemos conhecer o ser das coisas quando se nos aparecem, na condição de fenômeno. Todo o fenômeno percebido é integrado por matéria e forma. $\mathrm{O}$ que depende do próprio objeto constitui a matéria do conhecimento. A forma do conhecimento depende do sujeito que conhece. Portanto, conhecer é dar forma a uma determinada matéria, sendo que a matéria é a posteriori e a forma a priori, na compreensão kantiana, expressa na Crítica da Razão Prática.

Kant $(2011$; 2009) estabelece uma relação entre a formação do sujeito com o conhecimento e o juízo. Para realizar o juízo ou julgamento adequado de um determinado tema impõem-se a existência do conhecimento e sua fundamentação. É o conhecimento de 
algo que possibilita a realização de um juízo, efetuar um julgamento correto sobre um tema.

Nesta linha de reflexão, é a apreensão dos conhecimentos científicos historicamente elaborados, que se realiza pela dimensão do ensino, que sustenta adequadamente o julgamento, o qual também requer o aprimoramento da capacidade de julgar, que é um aperfeiçoamento da própria razão (KANT, 2009). O que conheço é a condição de possibilidade de realizar um julgamento, pronunciar um juízo, reconstruir os conhecimentos pela pesquisa e também propor determinadas ações em nível de extensão.

\section{Concluindo e para continuar pensando}

O princípio constitucional da articulação recíproca entre ensino, pesquisa e extensão, no âmbito das universidades brasileiras, conduz-nos para alguns desdobramentos fundamentais que dialogam com as intencionalidades e a identidade das universidades, a profissão docente e de sua formação e para a forma como é realizada a práxis da reprodução, produção e socialização dos conhecimentos, nestes espaços formativos. Este princípio constitucional aponta para o paradigma de universidade e aos objetivos do ensino em nível superior, centralizado na educação, pois

[...] numa sociedade organizada, espera-se que a educação, como prática institucionalizada, contribua para a integração dos homens no tríplice universo das práticas que tecem sua existência concreta: no universo do trabalho, âmbito da produção material e das relações econômicas; no universo da sociabilidade, âmbito das relações políticas, e no universo da cultura simbólica, âmbito da consciência pessoal, da subjetividade e das relações intencionais (SEVERINO, 2002, p. 11).

A abordagem feita neste trabalho, trazendo como tema o princípio da indissociabilidade entre ensino, pesquisa e extensão e o conhecimento vai além de ser uma opção feita por nós. Acreditamos ser esse um assunto que precisa continuar sendo (re)pensado na perspectiva triunitária, visto que tradicionalmente foi/é entendido de forma fragmentada e/ou dicotômica. Assim, os conceitos eram/são analisados unicamente como entidades separadas, ignorando-se a noção complexa existente entre eles.

A compartimentalização das várias áreas do conhecimento requer ser superada. As fronteiras estabelecidas entre as diversas ciências e de seus métodos específicos precisam ser diluídas, com a perspectiva da construção da interdisciplinaridade científica e formativa, à atender às intencionalidades da política universitária e à formar uma identidade acadêmica. Uma ciência contribuirá à outra nas elaborações e compreensões com as quais realiza o fazer pedagógico.

Integrar as três dimensões da universidade não significa anular metodologias e estabelecer um método único de fazer pesquisa, produzir saberes, mas acena para a sensibilidade e abertura de cada qual às contribuições, leituras, compreensões das outras ciências e dos outros métodos. É na mútua contribuição que se afirma a especificidade de cada ciência na construção dos espaços acadêmicos e do mundo comum. A relação triunívoca dá identidade às universidades, construindo as intersubjetividades.

A extensão universitária, no intuito de contribuir para tornar as condições concretas da existência humana mais adequada para todos e, em suas diversas dimensões, socializar os conhecimentos, articula conhecimentos empíricos e teóricos, os sócio-culturalmente constituídos com os acadêmico-científicos. É uma práxis que integra as exigências da eficácia do agir com as da elucidação do pensar e da reflexão. 
O fazer docente e as formas de construção, reprodução e socialização dos saberes, no âmbito das universidades, na perspectiva da indissociabilidade constitucional, relacionam-se com uma concepção e prática unitária dos conhecimentos. Cada campo do conhecimento humano permanece com a sua importância e formas de abordagem da realidade e a construção de sentidos societários. A compreensão unitária dos saberes não opera com a sobreposição ou supressão de algum destes ou de ciências, mas reconhece as diferenças e especificidades de cada qual visto que se complementam seja dialógica ou contraditoriamente. Cada é ciência formada por um conjunto de teorias que buscam compreender, conhecer os fenômenos, a realidade, as coisas. No entanto, nenhuma teoria ou ciência explica todos os fenômenos ou o fenômeno todo. Uma ciência requer a existência equitativa da outra, assim como a unidade das dimensões do ensino, da pesquisa e da extensão para a identidade universitária.

Para a realização de uma pesquisa há que se ter um conhecimento, embasado teoricamente, o qual orienta e baliza esta pesquisa, seus objetivos e seus procedimentos metodológicos. Ninguém pesquisa algo sobre o qual não possui nenhum conhecimento. É o saber propedêutico que possibilita a pesquisa, pois "ninguém chega a ser pesquisador, a ser cientista, se ele não domina os conhecimentos já existentes na área em que ele propõe a ser investigador, a ser cientista”, afirma Saviani (1984, p. 51). É o conhecimento aprofundado de um tema que possibilita a realização de uma pesquisa e a extensão. É o ensino sólido que poderá sustentar pesquisas e extensões relevantes.

A organicidade do tripé universitário constitui um movimento da formação superior constituindo uma síntese dos três movimentos acadêmicos que caracterizam a educação acadêmica universitária. São os processos do ensino, que constitui o ato de apresentar às novas gerações os conhecimentos historicamente elaborados pela humanidade, cabendo ao estudante a sua apropriação e aprendizagem; as dinâmicas da construção de novos conhecimentos, que requerem a realização da pesquisa seja esta empírica ou teórica; e a extensão que configura-se na relação com e na sociedade na qual a universidade está inserida, que possibilita a retro-alimentação do ensino e pesquisa. São os movimentos de mútua influência e contribuição: o ensino que baliza a pesquisa e extensão; e estas que desafiam e provocam a re-significação e re-elaboração e a construção de novos conhecimentos, os quais por sua vez provocam novas pesquisas e extensões universitárias.

O ensino situa o estudante na relação com as elaborações e produções científicas existentes, a pesquisa o situa com o seu desenvolvimento intelectual e possibilita a produção de outros saberes e a extensão como situação de confrontação de sua pesquisa com a aprendizagem anterior. Confronta-se na pesquisa e extensão os conhecimentos anteriormente apreendidos com as novas descobertas ou a confirmação do já conhecido. Consideramos isso importante em uma época na qual a especialização tem recebido muita ênfase. Por mais que a universidade seja organizada em cursos distintos, ela não pode deixar de lado sua marca registrada: a de ser unidiversidade.

\section{Referências}

ARISTÓTELES. Física I e II. Tradução Lucas Angioni. Campinas: UNICAMP, 2009a. .́tica a Nicômaco. 3. ed. Tradução Edson Bini. Bauru: EDIPRO, 2009b. Metafísica: ensaio introdutório. São Paulo: Loyola, 2002. v. 1.

BRASIL. Constituição da República Federativa do Brasil: 1988. 18.ed. Brasília: Câmara dos Deputados, 2002. Série textos básicos, n. 27. 
CATANI, Afrânio; OLIVEIRA, João. A educação superior. In: OLIVEIRA, Romualdo Portela de; ADRIÃO, Theresa (orgs.). Organização do ensino no Brasil: níveis e modalidades na Constituição Federal e na LDB. 2. ed. São Paulo: Xamã, 2007. p. 77-88.

CHAUÍ, Marilena. Convite à filosofia. 12. ed. São Paulo: Ática, 1999. n. 13 .

O que é ideologia. 42. ed. São Paulo: Brasiliense, 1997. Coleção primeiros passos,

FÁVERO, Maria de Lourdes de A. A dimensão histórico-política da nova Lei de Diretrizes e Bases e a Educação Superior. In: CATANI, Afrânio Mendes (org.). Novas perspectivas nas políticas de educação superior na América Latina no limiar do século XXI. Campinas: Autores Associados, 1998.

HEIDEGGER, Martin. Ser e Tempo. 7. ed. Tradução rev. e apres. Marcia Sá Cavalcante Schuback. Petrópolis: Vozes; Bragança Paulista: São Francisco, 2012.

KANT, Immanuel. O que é esclarecimento? Tradução Paulo Cesar Gil Ferreira. Rio de Janeiro: Via Verita, 2011.

Crítica da razão pura. Tradução Lucimar Coghi Anselmi; Fulvio Lubisco. São Paulo: Martin Claret, 2009. Coleção a obra-prima de cada autor, n. 3.

Crítica da razão prática. Tradução Paulo Barrera. São Paulo: Ícone, 2005.

LEITE, Flamarion Tavares. 10 lições sobre Kant. 4. ed. Petrópolis: Vozes, 2010. Coleção 10 lições.

PLATÃO. Diálogos. Tradução Edson Bini. Bauru: EDIPRO, 2008. v. 3.

SAVIANI, Dermeval. Escola e democracia. São Paulo: Cortez, 1984.

SEVERINO, Antônio Joaquim. Competência técnica e sensibilidade ético-política: o desafio da formação de professores. In: Cadernos FEDEP, n.1, fev. 2002. p. 7-20.

TARNAS, Richard. A epopéia do pensamento ocidental: para compreender as ideias que moldaram nossa visão de mundo. 4. ed. Tradução Beatriz Sidou. Rio de Janeiro: Bertrand Brasil, 2001.

\begin{abstract}
Nota
[1] Referente à teoria aristotélica das quatro causa, Chauí (1997) pondera que, em tese, as distintas relações entre as quatro causas explicam a realidade, o modo como existe e se modifica e a finalidade de sua existência. Porém, as quatro causas não possuem o mesmo valor. Há uma hierarquia, sendo a causa mais importante a da finalidade. Segundo, a teoria é uma concepção metafísica que busca explicar os fenômenos naturais e os fenômenos humanos, a realidade social. Qual seria a relação desta teoria de Aristóteles com a divisão social hierarquizada? Esta teoria "é a transposição involuntária para o plano das ideias de relações sociais muito determinadas. Quando o teórico elabora sua teoria, evidentemente não pensa estar realizando essa transposição, mas julga estar produzindo ideias verdadeiras que nada devem à existência histórica e social do pensador. Até pelo contrário, o pensador julga que com essas ideias poderá explicar a própria sociedade em que vive" (CHAUÍ, 1997, p. 8-10).
\end{abstract}

Recebido: abril/16 Aprovado: dezembro/16 